\title{
arena conta tiradentes: dilemas estéticos e ideológiicos do teatro de arena pós Qoolpe de 1964
}

\section{Mariana Figueiró Klafke*}

Artigo recebido em 02/10/2015 e aceito para publicação em 11/12/2015. * Mestranda em Literatura Brasileira da Universidade Federal do Rio Grande do Sul (UFRGS). E-mail: marianaklafke@gmail.com

\section{Resumo:}

Arena conta Tiradentes, de Augusto Boal e Gianfrancesco Guarnieri, utiliza um levante político do período colonial para falar do momento de 1967 , refletindo sobre o malogro das expectativas democráticas de inclusão popular que se viviam no Brasil dos anos 1950 e 1960, interrompidas pelo golpe de 1964 e pela ditadura que se instalaria a partir de então. Para o Teatro de Arena, grupo muito ligado à questão nacional-popular e que teve centralidade na produção cultural dos anos anteriores, lidando justamente com uma temática relativa à inclusão do povo no debate sobre os rumos do país, o golpe significou uma ruptura fundamental e exigiu uma revisão significativa dos horizontes ideológicos e estéticos. A partir de 1965, o Arena produziu uma série de musicais utilizando uma nova técnica, o Sistema Coringa, que procurou sintetizar sua trajetória estética e propor 
rumos para a nova situação política do país. Dentre esses musicais encontra-se Arena conta Tiradentes, objeto deste estudo. Por meio de uma leitura própria e da retomada dos principais estudos sobre a peça, procuramos refletir sobre os dilemas estéticos e ideológicos do grupo no conturbado pós-64.

\section{Palavras-chave:}

Teatro de Arena; Teatro e Política; Ditadura.

\begin{abstract}
:
Arena conta Tiradentes, by Augusto Boal and Gianfrancesco Guarnieri, uses a political upheaval of the Brazilian colonial period to talk about the moment of 1967, reflecting on the failure of the democratic expectations concerning popular inclusion that was experienced in Brazil in the 1950 s and the 1960s, and interrupted by the 1964-coup which set up a dictatorship. For Teatro de Arena, a group that had been closely linked to the national-popular issues and that had been central in the cultural production of the previous years (dealing precisely with themes related to the inclusion of the people in the debate about the future of the country), the coup represented a fundamental rupture and demanded a significant review of their ideological and aesthetic horizons. From 1965 on, Arena produced a series of musicals employing a new technique, The Joker System (Sistema Coringa), in which they sought to synthesize their aesthetic trajectory and propose directions for the new political situation of the country. Among these musicals is Arena conta Tiradentes, object of this study. Through a reading of our own and the reading of the main studies on the play, we aim to reflect on the aesthetic and ideological dilemmas of the group in this troubled post-64 period.
\end{abstract}

\section{Keywords:}

Teatro de Arena, Theater and Politics, Dictatorship.

Arena conta Tiradentes, de Augusto Boal e Gianfrancesco Guarnieri, foi encenada pelo Teatro de Arena pela primeira vez em abril de 1967, com direção geral de Augusto Boal, direção musical de Théo Barros, músicas de Gilberto Gil, Caetano Veloso e Sidney Miller, e cenografia de Flávio Império. O primeiro ato possui três episódios, que apresentam o corrupto governo de Cunha Menezes, o acirramento de tensões no governo Barbacena e a preparação da revolta. No segundo ato, dividido em dois episódios, acompanhamos o malogro da conjura, com a delação e prisão dos inconfidentes, o julgamento de todos os envolvidos na conjura e a execução de Tiradentes. Os fatos sucedem de forma linear, à exceção da sentença contra o alferes, que está no início, e do interrogatório de Tiradentes, que se distribui por toda a peça, reafirmando o caráter pretérito dos acontecimentos e induzindo a atitude pretendida diante dos fatos: interrogar e julgar (CAMPOS, 1988).

A peça em dois atos (ou Coringa em dois tempos, como lemos no texto) teve como base para pesquisa o Romanceiro da Inconfidência, de Cecília Meirelles, e os Autos da Devassa, mas não mantém fidelidade aos dados históricos. Assim como Arena conta Zumbi, Tiradentes utiliza um levante político do período colonial para falar do momento presente (1967), embora com uma análise política mais apurada e matizada do que a apresentada pelo musical anterior do Arena. Tiradentes se distancia da complacência de Zumbi e a crítica estende-se aos derrotados, mas cabe analisar no detalhe o funcionamento crítico no interior da obra. Na peça, povo e classe revolucionária não são rigorosamente a mesma coisa: em termos de classe, o vigor revolucionário é associado especificamente aos mineiros, setor econômico apontado como fundamental naquela conjuntura, e não ao "povo" de forma genérica. Cabe notar que, de toda forma, a acuidade da análise fica relativizada pela 
concentração das expectativas revolucionárias em torno da função protagônica do herói Tiradentes.

A peça inicia com um coro polifônico entoando a canção "Dez vidas eu tivesse, dez vidas eu daria...", tema recorrente na peça, seguida pela leitura da condenação de Tiradentes. O Coringa anuncia, após a leitura da sentença, que o Arena contará a história do crime. Temos aqui a primeira Explicação do Coringa, cuja importância justifica a reprodução:

Nós somos o Teatro de Arena. Nossa função é contar histórias. O teatro conta o homem; às vêzes conta uma parte só: o lado de fora, o lado que todo mundo vê mas não entende, a fotografia. Peças em que o ator come macarrão e faz café, e a platéia só aprende a fazer café e comer macarrão, coisas que já sabia. Outras vezes, o teatro explica o lado de dentro, peças de idéia: todo mundo entende mais ninguém vê. Entende a idéia mas não sabe a quem se aplica. O teatro naturalista oferece experiência sem idéia, o de idéia, idéia sem experiência. Por isso, queremos contar o homem de maneira diferente. Queremos uma forma que use todas as formas, quando necessário. "Arena conta Tiradentes" história de um herói da liberdade nacional. Por isso, dedicada a José Joaquim da Maya, que foi o primeiro homem a se preocupar com a liberdade no Brasil. Foi o primeiro e desde então, até hoje, todo mundo continua só pensando nisso (BOAL; GUARNIERI, 1967, p. 6o) ${ }^{2}$.

Diferentemente do que acontece em Arena conta Zum$b i$, primeira peça a utilizar-se, de forma incipiente, do Sistema Coringa, aqui os autores enfatizam largamente algumas explicações sobre o funcionamento da peça e a posição de quem conta a história. Trata-se em alguma medida de expor, para além da peça, o processo que levou a ela e as escolhas que ela implica. Notamos que na primeira explicação do Coringa ecoa o raciocínio de Boal sobre a trajetória do Arena, exposto no primeiro dos artigos que antecedem o texto da peça e elucida o novo sistema do grupo, que aponta esse momento dos musicais como uma síntese necessária entre a fase fotográfica (demasiadamente particular) e a fase de nacionalização dos clássicos (demasiadamente universalista).

Nesta explicação fica indicada também a dedicatória, que será abordada a seguir. A peça é dedicada a José Joaquim da Maya, estudante brasileiro que da França escreve a Thomaz Jefferson pedindo apoio para a Independência do Brasil. O desenvolvimento desta dedicatória enfatiza o contraste entre o tom sincero de Maya (indicado na rubrica) e o tom velhaco de Jefferson ("tom de velha e carinhosa mãe gôrda"). É de estranhar que uma peça na qual a intelectualidade é duramente criticada e o malogro da independência é creditado à falta de envolvimento popular seja dedicada a um estudante que vive na Europa e solicita ajuda estrangeira para libertar o país da metrópole. O que se mostra ali é a manutenção das relações exteriores imperialistas ("o Brasil deverá tão somente comprar o nosso bacalhau"), tema que aparece em outros trabalhos do Arena, mas o estranhamento que causa essa dedicatória, considerando o desenvolver da peça, é inevitável.

O primeiro ato é dedicado essencialmente a expor a situação política da colônia, em especial a troca entre o governador Menezes e Barbacena e a instituição da Derrama, e como se formaram os planos da Inconfidência. Tanto os intelectuais envolvidos quanto os poderosos com os quais nos deparamos (autoridades políticas e religiosas) são apresentados por meio de um humor mordaz e sarcástico, enquanto as figuras populares são tratadas em chave séria, mesmo quando não são simpáticas à causa de Tiradentes. Em alguns momentos da peça, figuras populares são expostas como alienadas, seja individualmente ou em coros coletivos, mas jamais ridicularizadas. O alferes, um idealista, é apresentado como ingênuo e um tanto amalucado, o que nos leva a questionar como 
se faria possível a identificação com este herói. Logo no primeiro episódio nos deparamos com uma cena que exemplifica estas duas questões, a caracterização de figuras populares como alienadas, mas sem ridicularizá-las, e a caracterização do herói como um idealista. Na capitania do Rio de Janeiro, Tiradentes está em uma casa de Pilatas, tratando os dentes de uma personagem, Mônica, com quem discute. A marcação do Coringa indica que "a tôda gente espantava. Tiradentes semeava vento" (BOAL; GUARNIERI, 1967, p. 71).

TIRADENTES: Todo poder vem do povo e em nome do povo vai ser exercido!

MÔNICA: E o povo lá tem cabeça prá essas coisas? TIRADENTES: Tudo que é preciso resolver, reúne o povo na praça e pergunta: afinal, o que é que vocês querem? E o povo responde: "Queremos pão! Queremos trabalhar!" E lá vem o pão, lá vem o trabalho! Nesse dia, Moniquinha, você vai ficar de boca mais aberta do que está agora!

MÔNICA (Para ela a conversa de Tiradentes é muito engraçada; tem tanta graça como se hoje êle falasse de Reforma Agrária, etc.) (À outra môça.): Ouve só, Deolinda! Quando eu digo que louco se trata a pau, não é à tôa! Cadê povo pra essas coisas, seu Alferes?! Cada um quer fazer sua fortuninha sozinho. E prá mim tá certo! E a rainha também tá. Pensá nos outros a trôco de que?

TIRADENTES (Empunhando ameaçador o ferro de dentista): Eta! Que dá vontade de abrir sua cabeça a ferro prá você entender! Numa República, tudo é de todos. Então, a gente pensa também nos outros porque os outros somos nós.

MÔNICA (Empurrando-o): Ai! Também não precisa me cortá a bôca!

TIRADENTES: Fica me irritando!

MÔNICA: Como é que vai juntá todo mundo quer". Cada um vai querer uma coisa, ninguém vai entendê. Só o que pode dá é um pau de acabá com o mundo!

TIRADENTES: É claro que não vai perguntá de um em um. Na praça se escolhe o Govêrno, que também é povo, e pensa que nem a gente. Aí sim o País fica rico. Mas só é rico quando cada um é também. Não é como agora...

MÔNICA: Vai dizê que essa terra não é rica?

TIRADENTES: Vou sim! Rico é Portugal! O Brasil só vai ficar no dia em que o dinheiro não sair daqui. O que é nosso, nosso! Trabalho nosso, nosso! De todos, menos dêles!

MÔNICA: Quem descobriu isso aqui? Antes era só matagal e os índios com tudo de fora! Foram êles que vieram e ajeitaram!

TIRADENTES (Terminando o trabalho): Caramba! Que houvesse mais brasileiros como eu!... MÔNICA: Seu Alferes, seu Alferes! Deixe como está que é prá não piorar. Isso aqui é Colônia! TIRADENTES: No mundo inteiro as colônias estão sé libertando. Só a gente está indo pra trás... (BOAL; GUARNIERI, 1967, p. 71-73).

O que chama a atenção na cena é que justamente no contraste com o discurso pragmático e realista de algumas figuras populares, como Mônica, fica mais evidente o caráter idealista e quixotesco de Tiradentes. O protagonista, nesses momentos, é construído como alguém absolutamente alienado das questões dos populares e incapaz de estabelecer diálogo produtivo com as classes baixas. Não era justamente isso que se afirmava sobre os intelectuais?

Outra cena em que este contraste com os populares se evidencia também se passa no Rio de Janeiro, ainda no primeiro episódio, em uma taverna. Tiradentes expõe seus questionamentos à ordem vigente sem nenhum cuidado, motivo pelo qual é considerado perigoso. 
HOMEM 2: Cala a boca, que êsse é o Tiradentes. (Apavorado.)

HOMEM 1: Êsse é doido varrido, sô.

HOMEM 2: Doido não, é perigoso. Vamos andando que eu não quero ser visto com êle. (Alto a Tiradentes.) Alferes: sou um homem de coragem, mas respeito a autoridade. $\mathrm{O}$ amigo tome tento. (Fala agressivo.) (Tiradentes faz menção de atacá-lo, e os dois fogem correndo.) TIRADENTES: Belos homens de coragem (BOAL; GUARNIERI, 1967, p. 80).

É nesse momento que Tiradentes conhece Maciel, que concorda com sua revolta e tem uma leitura e planos mais concretos para a situação. A leitura de Maciel é de que outras nações teriam interesse em um Brasil livre, por razões comerciais, e, portanto, a questão seria somente começar o levante. Para isso, se fazia necessário mobilizar gente com dinheiro e armas, o que Maciel diz poder fazer:

Francisco de Paula é meu cunhado e comandante da Tropa Paga. Gonzaga e Cláudio Manuel são meus amigos e homens de lei. O Padre Carlos, Rollim, o Coronel Alvarenga são gente séria que levanta gente. Pólvora se consegue. Uma ponta de lança no Rio, outra na Bahia e Minas se levanta (BOAL; GUARNIERI, 1967, p. 82).

Aqui começam propriamente os planos da Inconfidência, sem indicativo algum de participação popular. Os contatos de Tiradentes com as classes baixas são marcados pela impossibilidade de diálogo, pelo idealismo do herói, pela alienação dos populares em sua condição de oprimidos. Porém, considerando o malogro da conjura, é possível a leitura de que esses populares tinham razão desde o início ao apontarem a Tiradentes o perigo que corria, sendo mais realistas que o protagonista, e não alienados.

O tema, porém, é um pouco mais complexo. A ideia da participação popular passa por modificações no decorrer da peça. Neste primeiro ato, fica clara a ideia de que o povo não é propriamente ausente, mas vai se juntar à luta revolucionária quando ela começar - dependendo, para isso, do clamor de uma liderança. Um garimpeiro, a quem o Coringa questiona sobre a adesão popular no caso de alguém organizar a resistência, diz: "Ah, isso é mais do que certo. Estourou o fuzelê, nós tá. O difícil é estourá" (BOAL; GUARNIERI, 1967, p. 101). Há, inclusive, a noção de que existe uma classe fundamental no processo, os garimpeiros: "Quem quiser Independência/ o garimpo vá chamar/ pois são mil bocas douradas/ que num grito vão apoiar" (BOAL; GUARNIERI, 1967, p. 100) - desde que liderada por alguém. Porém, o Coringa enfatiza, ao final dessa canção, que ninguém foi chamar os garimpeiros para a luta. Essa tarefa malograda caberia a Tiradentes, pelo que se depreende de uma fala de Alvarenga: "Há um terceiro - Tiradentes - que com seu ardor nos mantém animados! E que terá a tarefa principal de esclarecer o povo para que ele nos apóie!" (BOAL; GUARNIERI, 1967, p. 114).

É preciso esclarecer também que, ainda que a peça leve invariavelmente à conclusão de que os intelectuais envolvidos na conjuração eram ética e politicamente execráveis, a apresentação de cada personagem tem particularidades, não se tratando, ao contrário do que acontece em Zumbi, de uma exposição tão maniqueísta, do bem contra o mal. Gonzaga, por exemplo, aparece a princípio como uma figura séria e comprometida, e aos poucos sua condição vai se demarcando, fortemente atrelada à ideia de futilidade. Enquanto Domingos Vieira, Silvério dos Reis e Cláudio Manuel da Costa aparecem desde o primeiro momento enredados em conciliações de interesses que indicam a fraqueza de suas convicções políticas (nota-se a ênfase no fato de que a eles interessa a ideia da independência, visto que a situação de colônia implica perdas econômicas), Gonzaga surge de início com discursos que efetivamente questionam a ordem instituída, ainda que logo fique claro que se trata somente do mundo das ideias (seu mote é "hipoteticamente"). 
Uma cena que exemplifica bem isso se dá no início do segundo episódio. O governador Visconde de Barbacena discute com o Tenente Coronel Francisco de Paula sobre a derrama e demais medidas da Coroa que serão aplicadas por ele quando chegam Domingos de Abreu Vieira, Tomás Antônio Gonzaga, Cláudio Manuel da Costa e Joaquim Silvério Dos Reis com reclamações. Rapidamente, porém, todos vão se acovardando, negando intenção de resistência e passando a responsabilidade adiante:

GONZAGA: E sobre todas essas medidas Vossa Excelência ainda pretende lançar a Derrama? BARBACENA: Estudo apenas a data.

GONZAGA: Saiba que os povos das Minas se levantarão!

BARBACENA: Meu dispositivo militar me garante a obediência e o apoio do povo. (A Francisco de Paula.) Não é verdade?

FRANCISCO: Meu regimento está preparado para tranqüilizar a população em vinte e quatro horas.

SILVÉRIO: Comigo não tem problema, porque eu sou bom vassalo e fiel; mas com essas medidas os donos de fábricas ficarão a pé e com a Derrama ficarão de rastros.

DOMINGOS: Comigo não tem problema, que eu sou dono de fábrica, mas escravo fiel de $\mathrm{S}$. M. Mas os que vivem de emprestar dinheiro, talvez não sejam tão bons vassalos como o Dr. Cláudio Manuel.

CLAUDIO: De minha parte eu me preocupo mais com as leis e as letras do que com os negócios. Mas gente existe que terá de escolher entre a morte e a revolta. Seria preciso saber se todos os comandantes são tão fiéis vassalos como o nosso Tenente-Coronel.

FRANCISCO: Soldado cumpre ordens.

BARBACENA: E Vossa Mercê, ouvidor Gonzaga? Embora vossa fidelidade não tenha sido
Vossa Mercê que tão bem sabe da índole do povo, Vossa Mercê que pensa?

GONZAGA: Não é necessário saber a índole, basta conhecer as matemáticas. Se as fábricas estão fechadas, se a extração de diamantes, só a faz a Coroa, se o crédito é extinto, a Derrama terá apenas um sentido simbólico, pois o ouro já terá sido todo embarcado.

BARBACENA: Poréma Derrama é ordem expressa! GONZAGA: Vamos examinar. A Coroa quer mais dinheiro. O País não tem. Portanto, existe a hipótese de não lançar a Derrama.

BARBACENA: É este o vosso conselho?

GONZAGA: Só estamos conversando por hipóteses. Se não se lançar a Derrama, existem duas hipóteses: a Rainha tanto pode concordar, como pode nomear outro Governador em seu lugar.

BARBACENA: Então, a Derrama é inevitável. GONZAGA: Neste caso também existem duas hipóteses: lançá-la por todos os atrasados ou só pelo último ano. Como o primeiro caso é totalmente inexeqüível, ainda resta a segunda hipótese.

BARBACENA: Talvez seja a solução.

GONZAGA: Mas neste caso o povo entenderá que se trata de uma primeira medida e que logo a Coroa exigirá o pagamento integral. Portanto, lançar a Derrama por um ano só, ou por todos os anos, vem a ser a mesma hipótese. BARBACENA (Diplomaticamente irritado): Senhor Gonzaga, afinal qual a vossa opinião? Vossa Mercê é a favor da hipótese de não lançar? GONZAGA: Eu vou confessar com tôda a sinceridade: eu sou a favor da hipótese! (BOAL; GUARNIERI, 1967, p. 88-90)

Na cena, vemos todos agindo de forma acovardada, mas entre eles há nuances. Enquanto Domingos, Cláudio e Silvério procuram atribuir responsabilidade aos outros, o que é uma canalhice a mais, Gonzaga ao menos tem, a princípio, coragem para alguns questionamentos. Em 
seguida, porém, já se demarca sua covardia no mote da hipótese, que será recorrente. Silvério dos Reis, por sua vez, desde o princípio aparece como muito esperto e acanalhado. A convicção com que trai os demais inconfidentes contrasta fortemente com a covardia e indecisão dos demais. De toda forma, cabe reafirmar que aqui, ao contrário do que acontecia em Zumbi, cada personagem tem suas características próprias, que interessam ao desenvolvimento dos argumentos da peça, não sendo o enredo definido simplesmente pelas ações de dois grandes blocos, protagonistas e antagonistas. Essa condição leva a necessidades cênicas diferentes das que observamos no musical anterior do Arena: Zumbi era uma peça minimalista em termos de adereços justamente por não haver especial relevância em definir quem era cada personagem para além da diferença entre brancos e negros, mas esse não é o caso de Tiradentes.

Com o esquema rotativo dos atores no Sistema Coringa, em que todos interpretam todos os personagens, com exceção do protagonista, que, visando à identificação maior, é encarnado por um só ator, foi necessário criar marcações com adereços que indicavam cada personagem, que os atores trocavam entre si, de forma a garantir que o público acompanhasse o enredo. Imaginamos que ainda assim deve ter sido confuso acompanhar as mudanças de atores, e questionamos o quanto a técnica do Sistema Coringa é realmente adequada para essa peça. Se é importante reconhecer cada personagem, pois cada um tem concretude e papel específico no enredo, não se tratando de tipos, por que manter o esquema de rotatividade de atores? Nos parece que Augusto Boal partiu da recomendação de Bertolt Brecht sobre a utilidade da rotatividade de atores durante os ensaios, de forma que fosse possível perceber o que é traço do intérprete e o que é próprio do personagem, e procurou aplicar à encenação como um dispositivo de distanciamento. Isso ajudaria a evitar que os espectadores criem empatia com os personagens antagonistas, que, não sendo representados pelo mesmo ator, ficam um tanto tipificados, menos pessoais.
Por isso mesmo o protagonista, Tiradentes, é o único a ser interpretado por um único ator, o que o torna mais particular, pessoal, humanizado, fácil de identificar-se. Acontece que o método de rotatividade de atores não parece algo orgânico a essa peça, já que justamente exige para o desenvolvimento de seu enredo a clara identificação dos personagens, que fica prejudicada pelo método. Ficamos com a impressão de que seguir as "regras do jogo" (as regras formuladas para o Sistema Coringa) tornou-se mais importante do que garantir o andamento claro da peça conforme suas exigências próprias.

O primeiro ato termina com contrastes entre dois planos paralelos: uma reunião na casa de Gonzaga, na qual se discutem abstrações e símbolos, e uma reunião na casa do Tenente Coronel Francisco de Paula Freire de Andrade, na qual são debatidos os planos concretos para a revolução. Aqui Bárbara Heliodora aparece criticando duramente o caráter idealista dos inconfidentes: "Bonito. Vocês gastaram tanto tempo fazendo o dístico que agora só ficou faltando fazer a independência" (BOAL; GUARNIERI, 1967, p. 112). Essa posição de Bárbara permite que seu marido, Alvarenga, tente livrar-se de sua culpa acusando-a durante o julgamento. O ato termina propriamente com a fusão das duas cenas e uma exaltação em crescendo do levante que está por vir.

O segundo ato, ou segundo tempo, tem como centro a prisão e o julgamento dos inconfidentes e a condenação de Tiradentes, mas começa com a delação de Joaquim Silvério dos Reis, em uma das cenas mais comentadas da peça, na qual o Coringa entrevista o personagem.

CORINGA: Ei, Joaquim Sílvério, o que é que você tem aí no bôlso?

SILVÉRIO: Não importa.

CORINGA: Todo mundo já sabe.

SILVÉRIO: Se sabe, por que pergunta?

CORINGA: Quero ouvir da sua bôca. 
SILVÉRIO: Se quer me ouvir, que me escute: é uma carta de delação. Vou agorinha mesmo entregar ao Visconde General.

\section{CORINGA: Por quê?}

SILVÉRIO: Porque não sou trouxa... Já ouviu o jeito dêsse Tiradentes falar? O Visconde já foi muito bom de ter deixado êsse homem sôlto até agora. Mas se deixou, êle que é muito esperto, deve ter algum plano. Não! Cá por mim já tomei minha decisão e resolvi que meu batizado particular vai ser hoje mesmo escondido. Essa Inconfidência não vai dar em nada mesmo, quero ser o primeiro a delatar... E estou dentro do prazo.

CORINGA (com meia ironia): Você sabe que a sua memória vai ficar manchada prá sempre?

SILVÉRIO: Sei. Vão me chamar de Judas, as criancinhas na Escola desde pequenininhas vão aprender a me odiar. Mas, e daí? Antes um traidor vivo e rico que um herói morto sem vintém. A lei portuguêsa não é sopa, meu amigo...

CORINGA: Quer dizer que prá você, trair ou não tanto faz?

SILVÉRIO: Vamos conversar a sério? Traição aqui entre nós está institucionalizada. É legal e até dá lucro. A Coroa não quer gastar dinheiro aqui prá manter uma polícia secreta. Qual a solução? Transformou cada cidadão num alcagoete em potencial. Muito justo. Quem denunciar contrabando fica com a metade dos bens seqüestrados. Metade prá êle, metade prá Coroa... Bom negócio...

CORINGA: Ao que leva o mêdo, heim Silvério? SILVÉRIO: Mêdo coisa nenhuma. Se valesse o risco, até que o mêdo a gente enruste. Mas vamos falar com franqueza: já pensou direito em quem está metido nessa rebelião? Um bandinho de intelectuais que só sabe falar. Porque a liberdade... a cultura... a coisa públi- quero ver. O outro lá comandante das tropas. O que quer mesmo é posição seja na República, na Monarquia, no comunismo primitivo, o que êle quer é estar por cima. Olha velho, dessa gente, a maioria está trepada no muro: conforme o balanço, êles pulam prá um lado. E eu aqui vou nessa? Mas nunca.

CORINGA: Então você não acredita mesmo nesse levante?

SILVÉRIO: Condições havia, mas agora não. Povo, que é o que resolve mesmo nessas horas, não se pode contar com ele. $O$ povo não se reúne na casa do ouvidor Gonzaga e muito menos na do Tenente-Coronel. E graças a Deus não vai mesmo. Já imaginou êsse povaréu de mazombos tomando conta disso? Virgem Nossa Senhora, não quero nem pensar. Pois não estavam falando em libertar os escravos? Com o tempo, êles vão acabar falando de Reforma Agrária... (BOAL; GUARNIERI, 1967, p. 124-125, grifos nossos).

Algumas questões fartamente comentadas nos estudos sobre a peça podem ser exemplificadas a partir desse trecho, que é muito rico. Chama atenção a consciência ampla e bipartida do personagem Silvério, que expressa, além de um discurso marcado pelo seu tempo como personagem, um discurso contemporâneo à escrita da peça (falando em Reforma Agrária, por exemplo, ou na alusão à traição institucionalizada, que cabe analisar se carrega paralelo com 1967). O personagem também apresenta em suas falas sinais de consciência de ator, aparentemente ligada à perspectiva de grupo do Arena, que procurou marcar com força a existência de posicionamentos ao contar a história. Quem pensa que os metidos na rebelião são um bandinho de intelectuais, Silvério ou o Arena? De onde emerge a ideia de que "povo é que resolve nessas horas"? Silvério, o antagonista por excelência, é provavelmente o personagem mais consciente da peça, capaz de explicar ao público, via mediação do Coringa, 
os meandros do acontecimento histórico. Esse fato, em contraste com a ignorância de Tiradentes, tem consequências importantes no entendimento da peça, que serão comentadas no decorrer deste artigo.

A peça segue com a exposição das prisões dos conjurados, e temos aqui outra cena famosa de Tiradentes, na qual há uma repetição do mesmo episódio com efeito de desmascaramento, sob comando do Coringa. Trata-se do quarto episódio, na casa de Alvarenga em Vila Rica, onde os inconfidentes comemoram o aniversário da filha de Alvarenga e são interrompidos pelo aviso da traição e da prisão iminente. A cena, em sua primeira versão, já tem algo de ridicularizante, visto que as mobilizações contrarrevolucionárias chegam aos personagens em meio a amenas conversas sobre a poesia e o amor. Mas o andamento geral é de reação digna, com planos de levar à frente o levante imediatamente. A cena é fechada com grande dramaticidade pelas declarações de amor de Marília e Gonzaga, que afirma: "Marília, entre dois grandes amores, a escolha é sempre dolorosa: entre o amor à Pátria, e o amor que tenho pela minha Marília bela, mais amo a Pátria, amor maior que inclui o dela!" (BOAL; GUARNIERI, 1967, p. 132). Porém, a seguir o Coringa esclarece que essa cena é uma tradição mineira, $\mathrm{e}$, na verdade, Alvarenga sequer havia morado com a família em Vila Rica. O que segue é uma segunda versão dos acontecimentos, que enfatiza a covardia dos conjurados ao tomarem conhecimento da traição e sua disposição livre de dúvidas de negar todos os planos. Somente Bárbara Heliodora, desde o princípio da peça, é uma espécie de voz crítica entre os próprios inconfidentes, mantém-se firme e procura impedir Alvarenga de também apelar à delação. Vemos ainda nesse episódio a profunda ilusão de Tiradentes em relação a Silvério, em quem mantinha confiança inabalável, e a traição, com direito a abraço análogo ao beijo de Judas.

O quinto episódio é dedicado propriamente aos julgamentos, nos quais Silvério funciona como uma espécie de promotor. Todos os conjurados procuram negar sua culpa, inclusive Tiradentes. Alvarenga chega a tentar culpar a própria mulher, como comentamos anteriormente. Após ver a defesa dos demais, Tiradentes resolve assumir sua participação no levante:

É verdade que se pretendia o levante. É verdade que me encontrei com Maciel no Rio e lhe disse que o Brasil não necessitava do domínio estrangeiro. É verdade que a todos falava de um Motim e Sedição contra a Coroa Portuguesa. É verdade que o povo sofre e que induzi muita gente a combater em Vila Rica. É verdade que o povo ignora que se pode libertar a si mesmo e que induzi muita gente a que armasse o povo para que se libertasse. É verdade que eu queria para mim a ação de maior risco e é verdade que se existissem mais brasileiros como eu o Brasil seria uma Nação florente. É verdade que eu desejava meu país livre, Independente, Republicano. É verdade que eu confiei demais, e é verdade que abandonei aqueles para quem outros diziam querer a liberdade. E é verdade que só os abandonados arriscam, que só os abandonados assumem, e que só com eles eu devia tratar. É verdade que eu tenho culpa e só eu tenho culpa. E é verdade que estou só (BO$A L ;$ GUARNIERI, 1967, p. 157-158).

Segue-se a sentença, sendo somente Tiradentes condenado à morte. Estranhamente, nesse momento o Coringa interage com Tiradentes, o único personagem que, por seu caráter naturalista, não entrava em contato com a realidade mágica criada por ele. Esse contato se dá no momento em que Tiradentes percebe seus erros. Trocam algumas palavras e um abraço. Tiradentes é executado (não há rubrica explicando como se realiza a cena do enforcamento) e o Coringa faz sua última fala: 
A Independência Política contra Portugal foi conseguida trinta anos depois da forca. Se Tiradentes tivesse o poder dos Inconfidentes; se os Inconfidentes tivessem a vontade de Tiradentes, e se todos não estivessem tão sós, o Brasil estaria livre trinta anos antes e estaria novamente livre todas as vezes que uma nova liberdade fosse necessária. E assim contamos mais uma história. Boa noite! (BOAL; GUARNIERI, 1967, p. 163, grifo nosso).

A peça é encerrada com a exortação do coro, que convoca o público: "Espanto que espanta a gente,/Tanta gente a se espantar/ Que o povo tem sete fôlegos/ E mais sete tem pra dar!/ Quanto mais cai, mais levanta/ Mil vezes já foi ao chão./ Mas de pé lá está o povo/ Na hora da decisão!" (BOAL; GUARNIERI, 1967, p. 163).

Repassado sumariamente o andamento da peça, passamos à análise das principais críticas a respeito da peça. Roberto Schwarz faz um comentário rápido, mas eloquente, sobre Arena conta Tiradentes em seu ensaio "Cultura e política, 1964-1969: alguns esquemas" (1978). Comentando a junção equivocada dos métodos de Stanislavski e de Brecht ${ }^{3}$ em uma só peça, Schwarz enfatiza o esvaziamento de uma polêmica estética e ideológica que tivera significado histórico ${ }^{4}$. Para o crítico, o impasse formal criado pela junção desses métodos corresponde a um momento em que a crítica ao populismo ainda não se completou, e, perante o fato de que as massas não são homogêneas, prefere-se uni-las pelo entusiasmo a separá-las pela análise crítica de seus interesses. Para realizar de fato teatro político, seria necessário que este último movimento fosse feito, mas Schwarz comenta ainda que os melhores momentos do Arena estiveram justamente ligados às suas limitações ideológicas e "à simpatia incondicional pelo seu público jovem, cujo senso de justiça, cuja impaciência, que têm certamente valor político, fizeram indevidamente as vezes de interesse revolucioná-
Sábato Magaldi analisa Tiradentes como "a história da Inconfidência Mineira revista como autocrítica da esquerda em face da política de hoje [1967 $]^{5}$. Augusto Boal e Gianfrancesco Guarnieri sublinharam, nos episódios de 1791, as correspondências com a situação brasileira atual, de modo a explicar a derrota de 1964" (MAGALDI, 1998, p. 125, grifo nosso). O autor enfatiza o paralelismo rigoroso entre os dois momentos históricos (1789 e 1964), conforme a apresentação da peça: "Inconfidência palaciana seria o seu epíteto pejorativo, bem como os incitamentos revolucionários, feitos no início da década de sessenta, sem a participação do povo, significariam um jogo de cúpula, destinado ao inevitável esvaziamento" (MAGALDI, 1998, p. 125). Magaldi expõe alguns paralelos históricos, como a analogia entre o governo de Cunha Menezes / Fanfarrão Minézio e o desenvolvimentismo do governo Kubitschek (comparando a construção da cadeia pública com a construção de Brasília) e a corrupção escandalosa do governo Ademar de Barros, bem como a questão da troca de governantes regida por interesses comerciais estrangeiros, traçando uma comparação entre o governo do conde de Barbacena, responsável por garantir o aumento do recolhimento de impostos e taxas para a metrópole, e o governo Castelo Branco, acusado de sufocar a economia nacional em prol de interesses imperialistas americanos.

As objeções que Magaldi faz ao espetáculo são, sobretudo, duas: o uso excessivo da música, que, diferentemente do que acontecia em Arena conta Zumbi, não se impõe pela qualidade, e o amesquinhamento das psicologias, principalmente a de Gonzaga, da qual o autor depreende que "Boal e Guarnieri pretenderam menos aprofundar a grandeza libertadora da Inconfidência Mineira e o seu valor simbólico na luta pela emancipação nacional do que identificá-la à pândega vigente no Governo João Goulart" (MAGALDI, 1998 p. 130). Nos parece que a crítica no sentido do amesquinhamento das psicologias parte de pressupostos e parâmetros fechados de análise de espetáculos somente dramáticos, nos quais o indivíduo é central, o que não é propriamente o caso de formas 
épicas de espetáculo, que estão no horizonte dos musicais do Arena. O ponto fundamental da crítica, entretanto, se encontra no que grifamos acima: a ideia de que há na peça uma autocrítica da esquerda, análise que destoa da leitura de outros intelectuais. Também é importante demarcar no texto de Magaldi a análise positiva que o autor faz sobre a junção de Stanislavski e Brecht, na qual o crítico não vê um problema estético e ideológico, como as demais leituras de que trataremos adiante.

Décio de Almeida Prado, em uma leitura oposta à de Sábato Magaldi, não vê autocrítica em Tiradentes. Em relação à pergunta que flui do texto de Tiradentes - a quem cabe a culpa pelo malogro do projeto revolucionário mineiro -, não podem restar dúvidas: àqueles que tinham algo a perder, o que não inclui o povo (que sequer esteve envolvido no processo da Inconfidência) ou Tiradentes (cuja imagem na peça passou por um recorte que o torna praticamente uma figura popular, e que, ademais, é apresentado como alguém que simplesmente foi enganado pelas más companhias).

A esquerda intelectual, com a consciência pesada pelo malogro de 1964, menos talvez pela derrota que pela ausência de luta, tomava o liberalismo burguês e a literatura não engajada como principais bodes expiatórios. Ah, não fossem os nossos aliados militares, os nossos aliados da Igreja, os nossos aliados da chamada burguesia progressista, e, sobretudo, os escritores, nossos aliados e pseudochefes, que bela revolução não teríamos feito! O Arena sacrificava Cláudio e Gonzaga (já sacrificados com a morte e o desterro) para poder manter de pé a cabeça (PRADO, 2007, p. 76).

Cláudia de Arruda Campos elabora uma análise de Arena conta Tiradentes que procura enfatizar, por um lado, os avanços da peça em relação a Arena conta Zumbi (ambos espetáculos são objeto de sua dissertação, publicada em livro ${ }^{6}$ ) e, por outro, as implicações políticas que as escolhas estéticas e ideológicas do Arena nesse momento deixam entrever. Como em Zumbi, Tiradentes tem como assunto um acontecimento histórico que se erige como modelo capaz de iluminar o presente (1967), tomando liberdades em relação aos relatos históricos disponíveis em prol da construção de um esquema analógico que propicie refletir sobre levantes de libertação de uma forma genérica, louvando e incentivando a resistência. Porém, em Tiradentes há uma construção mais complexa de análise do malogro de um movimento libertário, malogro este que o grupo procura esclarecer como totalmente evitável, apontando especialmente duas causas centrais: a composição do grupo revolucionário e a ausência do povo. Campos retoma as analogias históricas, já indicadas sumariamente por Magaldi, mas procura enfatizar o potencial de abstração que algumas delas carregam, possibilitando uma análise mais ampla dos movimentos do capital. A autora exemplifica com a questão da construção da cadeia pública e as canções que a acompanham, como a marcha-rancho "Critique menos e trabalhe mais": ao mesmo tempo em que constroem o cenário do período colonial, as canções apontam para uma crítica mais ampla de alienação do trabalho.

Campos argumenta que Tiradentes apresenta mais possibilidades de desvendar estruturas capitalistas (o que é essencial, considerando a pretensão de construir esquemas analógicos) por apresentar contradições dentro da mesma sociedade, já regida pela lei do lucro e do capital, e não oposição entre duas sociedades heterogêneas, como víamos em Zumbi. Aqui não há uma contraposição tão simplista como em Zumbi, mas sim um conflito de interesses mais complexo. Isso se reflete na caracterização dos personagens, que precisam ser reconhecidos por conta de seus interesses divergentes.

Semelhantes porque aristocratas, Silvério dos Reis, Domingos de Abreu Vieira, Cláudio Manoel 
da Costa têm interesses divergentes de acordo com a instituição social que cada um representa: o latifúndio, a indústria nacional nascente, o capital financeiro, respectivamente. A peça deixa ver que cada um está pronto a aproveitar-se do outro e que só vai uni-los a ameaça ao lucro de todos (CAMPOS, 1988, p. 102).

A limitação gritante dos inconfidentes é que todos têm algo a perder com a radicalização do movimento, e temem a participação popular, pois, por mais diferenças que tenham com a metrópole, maiores são as divergências com o povo. Os militares, por sua vez, só se dispõem a aderir ao movimento com a certeza da vitória e do comando. Os intelectuais, especialmente na figura de Gonzaga, ocupam-se de idealizar como será o país após a revolução, que deixam por fazer. Com homens tão vacilantes, a revolução estava mesmo condenada ao fracasso. Campos aponta que somente Tiradentes, o herói da peça, compreende a necessidade de incluir o povo na conjuração, chamando-o às armas, afirmação da qual discordamos. O que vemos na peça é a atribuição a Tiradentes dessa função, que não se realiza: seus contatos com figuras populares são todos marcados por uma distância de consciência e uma impossibilidade de diálogo gritantes, construindo a imagem do herói quase como um lunático idealista, que não enxerga o malogro evidente dos planos inconfidentes.

As limitações apontadas nos inconfidentes, ainda que procurem manter alguma coerência com o material histórico disponível, indicam, de toda forma, defeitos atribuídos pela esquerda aos maus combatentes7, fazendo com que o passado se refira ao presente e critique toda postura pseudorrevolucionária. Ao mesmo tempo, essas limitações expõem um discurso mais geral sobre posição de classe: não seria possível contar com indivíduos das classes altas para fazer uma revolução, já que no processo suas posições acabariam por ser questionadas e isso do povo, por outro lado, Campos aponta a predominância de exposição da alienação e do discurso conservador, com exceção da única classe apontada como revolucionária, os garimpeiros, apresentados na peça como setor economicamente fundamental da época. Porém, a exaltação do potencial revolucionário dos mineiros aparece nas canções e em uma única cena no discurso consciente e revoltado de um garimpeiro em uma taverna, mas não no desenvolvimento dos acontecimentos, dos quais eles ficam de fora.

Assim como em Zumbi, em Tiradentes o inimigo é um poder externo que age através do poder constituído internamente, os governantes que defendem os interesses da metrópole, porém eles não são o alvo das críticas mais mordazes, mas sim os conjurados, falsos revolucionários que permitem a crítica metafórica aos companheiros da véspera, pelo que se pode deduzir.

A partir da cisão de ponto de vista entre Coringa e função protagônica, o Arena tem intenção de construir uma peça que apresente crítica e modelo positivo de ação, através do herói. Dessa cisão resulta a constituição de dois planos distintos na peça, quase incomunicáveis: "O herói, confinado à consciência que seu universo dramático the pode conferir, corre cego em direção à desgraça, enquanto o Coringa, integrante de uma realidade dramática diversa, manipula os dados, constrói cenas, move personagens de modo a demonstrar a inexorabilidade do desastre" (CAMPOS, 1988, p. 108). Campos enfatiza, porém, que essa divisão de perspectiva é puramente formal, e a tensão se resolve no sentido de que ambas as perspectivas apontam para uma mesma conclusão. Os universos, por fim, acabam por encontrar-se na interpretação unificada dos acontecimentos. Tiradentes, ao compreender seus erros, rompe com os limites naturalistas que vinham sendo respeitados até então e entra no teatralismo geral ${ }^{8}$, conversando com o Coringa e cantando com o coro. A conclusão que se espera do espectador é reforçada por ambos os lados: "um pela razão, outro pelo 
envolvimento emocional, nos oferecem a compreensão do erro, a indicação do caminho e do modelo a seguir" (CAMPOS, 1988, p. 109). Falta explicar a cegueira do herói, mas a autora chama a atenção para a coerência interna desse dado, já que é preferivel nada compreender a ver o problema e nada fazer para evitá-lo. Reside aí, na visão de Campos, o principal dilema da peça: a posição do herói é enfraquecida, sendo possível ter simpatia por ele, mas não se identificar no plano racional.

Eldécio Mostaço é quem faz as críticas mais contundentes e sem concessão alguma à peça, definida como "um dos mais acabados exemplos de pura ideologização da recente história do teatro brasileiro" (MOSTAÇO, 1982, p. 91). Mostaço enfatiza o caráter fixo do Sistema Coringa, que faz pensar em jogo, com árbitro (o Coringa), inclusive, para demonstrar o maniqueísmo da teoria e da peça. A partir de uma citação dos ensaios de Boal sobre o sistema - cuja descontextualização tem o preço de manipulação do argumento, ignorando o quanto Boal teorizou esteticamente sobre o fazer teatral nestes textos e enfatizou largamente a necessidade de buscar formas que expressem os novos conteúdos pretendidos - o crítico afirma que o diretor exclui de seu raciocínio as categorias estéticas, vendo validade somente em atividades com saldo político imediato.

O Arena, que já possuía uma perspectiva sobre a história, pretende agora aprofundar uma intervenção sobre a história, uma ação. A estética já não é mais do que mera arma de incitamento e o teatro senão o lugar de encontro da seita para ouvir a palavra de ordem a ser cumprida na rua. A mobilização atinge seu grau máximo, onde o mínimo desejável é que o espectador, saído do teatro, apanhe a primeira arma e comece a lutar (MOSTAÇO, 1982, p. 93).

Mostaço enfatiza que essa radicalização depende de uma análise de conjuntura que aproxime os dois momentos históricos (1789 e 1967), ou seja, implica a leitura de que é necessário se afastar das cúpulas e tornar-se cada um herói, já que o povo não está mobilizado e não tem consciência de seu papel histórico: "O racha de 67, de onde surge a ALN9 e suas táticas que preconizava, pela via cubana, a luta armada como única saída para os povos oprimidos, encontra na montagem de Tiradentes não apenas uma analogia estética como a primeira mobilização de opinião pública a nível de sua propaganda" (MOSTAÇO, 1982, p. 94). Nos parece que falta esclarecer como Mostaço mantém firme seu argumento tendo em vista que a breve análise do Sistema Coringa feita pelo crítico tem como pressuposto aceitar que a orientação estética do Arena naquele momento é o realismo socialista e as teses de Lukács, mas sua postura ideológica seria contrária à postura pecebista, que recusava a opção da luta armada.

A análise de Iná Camargo Costa para Arena conta Tiradentes, que se encontra em A hora do teatro épico no Brasil, parte dos pressupostos dos ensaios de Anatol Rosenfeld sobre o Sistema Coringa e da dissertação de Cláudia Arruda Campos sobre os musicais Arena conta Zumbi e Arena conta Tiradentes, o que permitiu à autora focar-se especialmente nas implicações ideológicas da analogia entre os dois momentos históricos que o Arena propõe com a peça. Segundo Costa, em 1967 já havia se firmado a versão de que não houve resistência ao golpe ${ }^{10}$, justamente porque a frente ampla progressista que sustentaria as reformas em vista no país era muito frágil, fundada em ilusões de alianças de classe.

Note-se a eficiência do golpe: em pouco mais de dois anos consolida-se a versão de que em 1964 não houve resistência (subentenda-se: não houve derramamento de sangue, assassinatos, perseguições etc., como de hábito na história do Brasil, cujas transições sempre foram realizadas com "muita cordialidade"). Não havendo resistência, fica automaticamente demonstrada a inexistência de 
avanços no período anterior e conseqüentemente ficam desmoralizados todos os que se supunham a um passo do poder, "apoiados" nos avanços das massas. Por esse processo fraseológico a meia-verdade transforma-se em toda a verdade, pois se é certo que direções como o PCB e o PTB foram completamente desmascaradas pelos acontecimentos e, estas sim, caíram sem oferecer resistência, também é verdade que em mais de um setor (sobretudo no campo) tais direções já tinham sido ultrapassadas algum tempo antes das operações militares. O próprio episódio da "sindicalização do trabalhador rural" já as mostrara correndo atrás do prejuízo. E agora elas mesmas e seus sucessores, tratando de encontrar seu lugar na "contra-ofensiva" organizada em torno da Frente Ampla, até porque não tinham mesmo interesse em encarar aqueles fatos que os obrigariam a uma autocrítica de maior alcance, trataram de fazer coro ao "programa democrático", colaborando para que se criasse uma espécie de abismo separando a "oposição responsável" dos que então se apresentaram como a esquerda propriamente dita (COSTA, 1996, p. 131-132).

Dentro dessa "esquerda propriamente dita" haveria um movimento geral que põe a crítica no lugar da autocrítica necessária, de forma que, esclarecidas as responsabilidades pelo malogro da movimentação pré-64 e feitas as denúncias das posturas que teriam levado a esse quadro (reformismo, reboquismo, populismo), o momento seria de indicar rumos e métodos. Para Iná Camargo Costa, Arena conta Tiradentes dá forma teatral a essas propostas, desde a seleção do assunto, uma rebelião malograda, até a seleção de material focada em expor a Inconfidência como uma mera conspiração de intelectuais despreparados para levar a cabo uma revolução.
Na construção da tese de Costa, que debate o desenvolvimento do teatro épico no país, Arena conta Tiradentes figura como uma peça importante e eloquente. No afã de fazer um teatro que exponha crítica, mas também aponte caminhos, o Arena despolitiza a polêmica brechtiana, que para além da importância estética tem significado histórico, como Schwarz já havia enfatizado anteriormente. Para a autora, Brecht acaba por ser apresentado como somente mais uma possibilidade de consumo, a ser mobilizado conforme o gosto, independentemente do assunto.

Forjado, assim como o teatro de Piscator, no interior da luta de classes, o teatro de Brecht é uma arma nessa luta. Quando o movimento entra em eclipse-ocorrência normal depois de uma derrota como a de 1964 - não são muitos os capazes de perceber como continuar usando essa arma nas novas condições políticas de produção cultural. A história da dramaturgia brasileira nos anos 60 mostra que poucos dos que se engajaram nessa luta conseguiram sobreviver estaticamente à derrota. Uma das razões foi a dificuldade de encará-la - e examiná-la - como tal, que já está expressa no show Opinião e em Zumbi (COSTA, 1996, p. 138).

Lidando com o objetivo de criticar uma revolução, mas salvar a ideia de sua possibilidade, o Arena exuma um herói nacional como modelo de conduta. Porém, enfatiza Costa, o grupo parece não se dar conta de que sua peça reforça a opinião que conservadores têm sobre revolucionários: "são, na melhor das hipóteses, idealistas, sonhadores, visionários (Tiradentes), e, na pior, literatos românticos (no sentido adjetivo), covardes, desfibrados e sem qualquer noção das exigências da ação política" (COSTA, 1996, p. 138). O argumento de Costa é de que, com essas escolhas, o Arena encena alegoricamente a visão dos vencedores de 1964, ou seja, parece corroborar a ideia de que havia uma "conspiração de esquerda" em 
andamento e de que não houve firmeza para resistir às investidas contrarrevolucionárias.

A chave desse acordo com Silvério (um TRAIDOR!) é a ideia de que nossos revolucionários de 1789 (como os de 1964) estavam "em cima do muro" e, portanto, sozinhos, não apenas porque o povo estava ausente, mas porque fora afastado dos seus preparativos. Ora, como qualquer iniciante de estudos em matéria de política sabe, uma "revolução" que exclui o povo de seus planos chama-se conspiração - aliás, sinônimo de conjura ou inconfidência. Para ser consequente com o que diz o Curinga, deve-se inferir que em 1964, assim como D. Maria I em 1789, o que os militares fizeram foi apenas desbaratar uma desajeitada conspiração. Mas não era isso o que diziam os militares em 1964, numa tão espantosa quanto cínica inversão das posições? (COSTA, 1996, p. 140).

De acordo com a autora, com um grupo teatral dito de esquerda expondo com força sua rejeição às experiências pré-64, não surpreende que grupos que não tiveram propriamente ligação com esse cenário tomassem a frente de um teatro revolucionário no país daí por diante. Estamos falando principalmente do Teatro Oficina e especialmente da famosa montagem de $O$ rei da vela, sendo praticamente consensual, até mesmo entre os membros do Arena, a tomada de frente do grupo na história de um teatro político no Brasil nesse momento. Iná Camargo Costa se coloca de forma crítica em relação ao trabalho do Oficina nesse sentido, o que não poderemos expor no momento, mas essa questão é o cerne, por exemplo, da dissertação de Sonia Goldfeder, Teatro de Arena e Teatro Oficina: o político e o revolucionário. O objetivo central de Goldfeder é, através da análise comparativa das peças Arena conta Tiradentes e $O$ rei da vela, demonstrar que o Arena fazia um teatro político de cunho didático, enquanto o Oficina fazia um teatro revolucionário.
Goldfeder propõe uma leitura do texto de Tiradentes considerado em três níveis: exposição da situação, crítica e convocação à mudança, sendo recorrentes os recursos didáticos em todos os casos. Esses três níveis seriam desenvolvidos de forma intercalada em uma divisão também tripartida de planos: o da história/estória, o do julgamento e o do comentário. A autora enfatiza que o que move o desenvolver da peça é justamente o nível do comentário, que explica as cenas, ressaltando o caráter didático da peça. Além do Coringa, o coro é essencial nesse sentido, tendo suas intervenções efeitos diversos, que podem corroborar ou criticar algo dito por algum personagem. "Cabe ao Coro o anúncio do acirramento das tensões a nível político, quando, dando voz a alguns personagens, didaticamente expõe o aprofundamento dos conflitos. Seu discurso é sempre crítico-didático" (GOLDFEDER, 1977, p. 25).

Goldfeder procura enfatizar que dificilmente em Tiradentes um problema é somente apontado, mas vem acompanhado de alguma convocação à resistência. Para a autora, essa é a principal diferença entre o teatro que o Arena leva aos palcos nesse momento e as montagens do Oficina, em especial $O$ rei da vela: enquanto o Arena se pautaria por um teatro didático, que aponta falhas e ao mesmo tempo procura sugerir soluções ou modelos de ação, o Oficina estaria orientado para uma denúncia das classes dominantes, sem essa preocupação de apresentar modelos positivos.

Nota-se como ponto comum entre as críticas apresentadas, em especial as de Mostaço e Goldfeder, uma disposição prévia a ler o texto de Arena conta Tiradentes como esquemático e limitado ao didático, o que, ainda que contenha alguma verdade, acaba por elidir a ampla elaboração estética que subjaz a essa construção, além de perder de vista seu lugar na dinâmica do desenvolvimento do teatro nacional, que vinha incorporando Brecht em uma conjuntura deslocada, não sendo somente as experiências do Arena a conter alguma estranheza 
nesse sentido. Cabe enfatizar, de toda forma, que a grande inventividade de Tiradentes está no que também é sua maior fragilidade: a cisão do ponto de vista formada a partir do uso de duas funções fixas que se contrapõem, o coringa e o protagonista. Com o objetivo de fazer crítica e ao mesmo tempo apresentar um modelo positivo, o Arena recorre a esses dois recursos, de forma que o espectador se distancie da cena até certo ponto, mas ainda possa identificar-se com o herói, Tiradentes.

O dilema fundamental do Teatro de Arena naquele momento era a necessidade de fazer crítica (analisando e desmascarando uma revolução abortada) e ainda assim propor um modelo positivo de ação. Esse problema político tem profundas implicações estéticas e ideológicas no trabalho do Arena, como vimos. Se por um lado essas questões prejudicam o acabamento formal do espetáculo, por outro é indispensável notar o quanto esses descompassos dão testemunho de um momento histórico que atravessou com força um ponto de desenvolvimento importante do teatro brasileiro, deslocando suas coordenadas de forma eloquente.

\section{Referências bibliográficas}

BOAL, Augusto; GUARNIERI, Gianfrancesco. Arena conta Tiradentes. São Paulo: Livraria Editora Sagarana, 1967.

CAMPOS, Cláudia de Arruda. Zumbi, Tiradentes (e outras histórias contadas pelo Teatro de Arena de São Paulo). São Paulo: Perspectiva, 1988.

COSTA, Iná Camargo. A hora do teatro épico no Brasil. São Paulo: Paz e Terra, 1996.
GOLDFEDER, Sonia. Teatro de Arena e Teatro Oficina - o político e o revolucionário. Dissertação (Mestrado em Ciências Sociais) - Unicamp, 1977.

MAGALDI, Sábato. Arena conta Tiradentes. In: Moderna dramaturgia brasileira. São Paulo: Perspectiva, 1998. p. 123-130.

Um palco brasileiro: o Arena de São Paulo. São Paulo: Editora Brasiliense, 1984.

MOSTAÇO, Eldécio. Teatro e política: Arena, Oficina e Opinião (uma interpretação da cultura de esquerda). São Paulo: Proposta Editorial, 1982.

PRADO, Décio de Almeida. O teatro brasileiro moderno. 3. ed. São Paulo: Perspectiva, 2007.

SCHWARZ, Roberto. Cultura e Política, 1964-1969: alguns esquemas. In: O pai de família e outros estudos. Rio de Janeiro: Paz e Terra, 1978. p. 61-92.

\section{Notas}

${ }^{2}$ Optamos por reproduzir as citações do texto da peça literalmente conforme constam no livro, ou seja, mantendo a ortografia vigente quando da sua publicação em 1967.

${ }^{3}$ Resumidamente, Stanislavski foi a figura central de uma revolução no modo de atuar ao recomendar a identificação do ator com o personagem interpretado, penetrando ao máximo emocionalmente em seu mundo. Isso foi um grande avanço em direção a uma atuação menos grandiloquente, que permitia levar novos temas aos palcos - em especial as peças de Tchekhov, cujo movimento depende muito do estado interno dos personagens. Brecht, por sua vez, é conhecido pela formulação mais acabada do que chamamos de teatro épico, uma forma que, em contraponto ao drama propriamente dito, permite narrarfatos passadose inserir comentários sobre os acontecimentos. Isso estabelece certa distância interpretativa e leva a uma postura mais 
crítica do espectador, incitado a analisar a situação e não a aderir a algum personagem identificando-se com sua experiência e suas emoções. Brecht recomenda, por exemplo, que os atores não sejam os personagens, mas sim mostrem como os personagens são. Não existe ruptura absoluta entre os trabalhos de Stanislavski e Brecht, mas há uma polêmica histórica que deve ser levada em conta: Stanislavski foi a referência oficial para o teatro soviético no período stalinista, enquanto Brecht foi execrado. Essa polêmica política e ideológica tem grande valor na história das ideias de esquerda.

${ }_{4}^{4}$ Concordamos com Schwarz sobre o fato de que a junção dos métodos de Stanislavski e Brecht em uma única peça leva a um impasse formal e ideológico. A identificação com o protagonista stanislavskiano tende a ser mistificadora por depender de adesão pouco racional, já que é esse o personagem de consciência mais limitada por conta de sua condição naturalista. Além do sentido político, em que a polêmica entre os métodos fica diminuída quando o Arena parece considerar ambos simplesmente como opções de um amplo repertório formal disponível, cria-se um dilema estético com essa sobreposição: ao utilizar distanciamento crítico para tratar dos antagonistas e identificação emocional para tratar do protagonista, as partes ficam incomunicáveis e o protagonista sai diminuído em seu tratamento melodramático. Essa questão será mais fartamente comentada na minha dissertação de mestrado, da qual esse texto é uma parte. Anatol Rosenfeld trata minuciosamente dessa questão no artigo "Heróis e Coringas", presente em seu livro $O$ mito e o herói no moderno teatro brasileiro, publicado pela Editora Perspectiva em 1982.

5 O ano da publicação é 1998 , mas a crítica em questão foi escrita em 1967. O "hoje" do autor se refere, portanto, a este ano.

${ }^{6}$ CAMPOS, Cláudia de Arruda. Zumbi, Tiradentes (e outras histórias contadas pelo Teatro de Arena de São Paulo). São Paulo: Perspectiva, 1988.

7 Reproduzo aqui o argumento da autora, que não define mais concretamente a que esquerda se refere.

${ }^{8}$ Com o termo "teatralismo", procuramos aqui enfatizar o contraste com o registro naturalista em que o protagonista se encontrava. "Teatralismo" se refere ao registro fantasioso que o Coringa comanda, mobilizando diversos recursos teatrais não-realistas.

${ }_{9}^{9}$ Ação Libertadora Nacional (ALN), organização política que participou da luta armada contra a ditadura no Brasil. ${ }^{10}$ Iná Camargo Costa argumenta que a ideia de que não houve resistência ao golpe se firmou como verdade, mas não necessariamente concorda com isso. $O$ que a autora afirma é que essa versão se deve ao fato de que não houve resistência institucional, de partidos políticos de esquerda, mas outras formas de resistência aconteceram. Essa é também a posição da autora deste artigo. O que Costa está apontando e nos interessa aqui é que o Teatro de Arena parece corroborar essa versão de ausência de resistência em sua peça. 